\title{
APORTACIONES DE SALVADOR VILA, RECTOR DE LA UNIVERSIDAD DE GRANADA, AL ESTUDIO DEL DERECHO ISLÁMICO
}

\author{
M. a Jesús Viguera MoLíNS \\ Universidad Complutense
}

Es mérito de los organizadores de esta II Joseph Schacht Conference el haber procurado que alguna de sus intervenciones traten sobre la relación establecida entre la ciudad de Granada y los estudios de Derecho islámico. Esa relación se inauguró, desde la Universidad de Granada y desde su Escuela de Estudios Árabes, con la presencia y la labor de Salvador Vila Hernández, en ambas instituciones, entre 1933 y 1936. Por esa relación me parece muy oportuno que - aquí y ahora - recordemos al prof. Vila y repasemos su contribución, brillante y fugaz, pero también pionera y ejemplar, y dentro de sus circunstancias paradigmáticas, a la Historia del Derecho islámico.

Granada fue la ciudad donde Salvador Vila enseñó «Cultura árabe: instituciones musulmanas», como Catedrático de su Universidad (entre diciembre de 1933 y julio de 1936) y como Encargado de Sección y Profesor en la Escuela de Estudios Árabes de Granada (entre enero de 1934 y verano de 1936); fue la ciudad cuya Universidad dirigió como Rector (pocos meses, entre abril y julio de 1936), y fue la ciudad donde prematura y trágicamente murió, en el verano de 1936, al poco tiempo de estallar la guerra civil.

Todo esto, como vemos por las fechas hasta ahora mencionadas, ocurrió muy deprisa, demasiado deprisa y demasiado agitado e inmerso en gravísimas circunstancias externas, pero lo importante es que ocurrió, y que trajo hasta aquí las primicias, la convicción vocacional, la definición estudiosa y, seguramente, algunos medios básicos y ambientales, para establecer que era posible trabajar, aquí, en esta ciudad, sobre Derecho islámico.

Cierto es que esta posibilidad de trabajar aquí sobre Derecho islámico, la que en Granada inició el prof. Vila, se truncó enseguida, con su trágica muerte, pero cierto es también que aquí - y no en otra Universidad española - se reanudará el trabajo, acometido por varios universitarios en conexión, sobre Derecho islámico, algo más de un cuarto de siglo después, con una serie muy rica de contribuciones, dirigidas por Jacinto Bosch Vilá (1922-1985) y realiza- 
das por un grupo de alumnos suyos, contribuciones que serán recordadas en la siguiente conferencia*.

Pero establezcamos ya que esa vinculación, entre lo que el prof. Vila inició y lo que más tarde aquí se desarrolló, de forma coordinada, fue establecida como una «continuidad» y así explícitamente reconocida por el profesor Jacinto Bosch Vilá, Catedrático a su vez de Historia del Islam en la Universidad de Granada, cuando, en 1976, en el cuarenta aniversario de la muerte del profesor Vila, publicó su «Evocación del Dr. Salvador Vila Hernández, Catedrático de 'Cultura árabe: instituciones musulmanas'»', señalando: «porque queremos reparar olvidos ${ }^{2}$ [hacia Salvador Vila] a quien tenemos por nuestro inmediato antecesor en la cátedra, por razón de sus estudios, pese al vacío de casi un cuarto de siglo; porque en aquellos años [de su muerte] — yo era un adolescenteno se le dio tal vez el realce que científicamente merecía como gran promesa y, a la vez, luminosa realidad en el campo de los estudios histórico-jurídicos islámicos que cultivamos, queremos reavivar aquí, en estos Cuadernos [de Historia del Islam], su figura».

Este tipo de reconocimientos, aparte de su posible carga abstracta de convencionalismo y cortesía, tiene también, sin duda, una vertiente muy concreta y expresiva, porque todos sabemos, en nuestra experiencia académica, que el establecimiento de temas y el cultivo específico de vías de trabajo suelen constituir herencias científicas considerables, y que laborar sobre un campo de investigación significa también abrir la puerta a quienes quieran continuarlo y ampliarlo después. Así, el prof. Bosch Vilá terminaba su citada «Evocación» expresando que «el año antes de su fallecimiento, el Dr. Salvador Vila Hernández estaba dedicado a trabajos de investigación sobre instituciones y formularios notariales de la España musulmana, estudios que, entre otros, procuramos fomentar, no sin dificultades, en nuestra cátedra,

\footnotetext{
* Se refiere a la pronunciada por el Prof. Javier Aguirre Sádaba, «Granada y los estudios de derecho islámico», en la sesión inaugural del II Congreso Joseph Schacht sobre teoría y práctica en el derecho islámico, Granada, diciembre de 1997.

${ }^{1}$ Cuadernos de Historia del Islam (publicaciones del Seminario de Historia del Islam. Universidad de Granada), 7 (1975-1976), 173-176, más dos fotografías: una reproduciendo el retrato del prof. Vila, en el rectorado de la Universidad de Granada, y otra reproduciendo una carta autógrafa del prof. Vila al Secretario General de dicha Universidad, con fecha 16 de diciembre de 1933, acerca de su toma de posesión de la Cátedra de «Cultura árabe: Instituciones musulmanas», en Granada.

${ }^{2}$ En la nota 1 de su artículo, Jacinto Bosch Vilá advierte cómo no fue citado Salvador Vila en los siguientes cstudios sobre el arabismo español: Monroe, J. T., Islam and the Arabs in Spanish Scholarship (sixteenth Century to the present), Leiden, 1970; Cortabarría, A., El arabismo en la España contemporánea, Las Caldas de Besaya, 1968; Castellano Texeira, S., «Los estudios árabes en España», Kevista Nacional de Educación, 1947, 3-12.
} 
como homenaje a nuestro antecesor y en su memoria». Ahí está, pues, expresado el nexo del cultivo de temas de Derecho islámico en Granada: cultivo interrumpido, y a la vez conectable, entre los años treinta y los años setenta, hasta hoy.

Los datos biográficos, académicamente principales, del prof. Vila han sido revelados en los estudios que sobre él se han publicado $\mathrm{ya}^{3}$ : nació en Salamanca, el 2 de agosto de 1904. Y como indicó M. Fierro ${ }^{4}$ «pursued his studies at the University of Salamanca in both Humanities and Law. In April 1927 he obtained his Doctorate in 'Filosofía y Letras' with his study of Ibn Mugith's wathä'iq. Between 1928 and 1929 he studied in Berlin with the support of the 'Junta para la Ampliación de Estudios'5. After serving as Assistant at Madrid University $^{6}$ and at the 'Escuela de Estudios Árabes' (Madrid) ${ }^{7}$, he became Professor of Islamic Institutions at Granada University».

Hay una cierta contradicción sobre la fecha exacta de su muerte, lo cual revela también sus circunstancias violentas y el ambiente: su expediente oficial ${ }^{8}$, conservado en la Universidad de Granada ${ }^{9}$, trae el apunte de que «Cesó en el cargo de Catedrático por fallecimiento en 23 de octubre de 1936», y es la fecha ofrecida por Bosch ${ }^{10}$, que sin duda tuvo en cuenta este expediente; pero parece - según testimonios que recuerda el prof. López García ${ }^{11}$ - que fue fusilado «en fecha no precisada de la segunda mitad de agosto», desde luego de 1936.

\footnotetext{
${ }^{3}$ Bosch Vilá, J., «Evocación del Dr. Salvador Vila Hernández» (citada en la nota 1); Pérez Prendes, J. M.., «Borrador para un recuerdo», Ideal (Granada), 1976; López García, B., «Salvador Vila Hernández, arabista y universitario, en el cincuenta aniversario de su muerte», Olvidos de Granada, 15 (1987), 45-48; Fierro, M., «Spanish scholarship on Islamic Law», Islamic Law and Society, 2 (March 1995), 43-70, espec. p. 56.

${ }^{4}$ Fierro, M., «Spanish scholarship on Islamic Law», 56.

${ }^{5}$ Sin embargo, parece que no recibió su beca para estudiar en Berlín directamente de la Junta para Ampliación de Estudios e Investigaciones Científicas, sino de su propia Universidad de Salamanca. Véase lo que enseguida apuntamos al respecto.

6 «Auxiliar temporal en la Facultad de Letras de la Universidad Central, por concurso-oposición», desde el 20 de octubre de 1930 al 15 de diciembre de 1935, según indica la «Hoja de Servicios» de S. Vila, a la cual más adelante haremos referencia.

${ }^{7}$ Entre octubre de 1932 y diciembre de 1933 fue «Adjunto de Sección en la Escuela de Estudios Árabes de Madrid».

8 «Universidad de Granada. Profesorado Numerario y Auxiliar de los Establecimientos Públicos de Enseñanza. Hoja de Servicios. Don Salvador Vila Hernández. Expediente: Catedrático de la Fac. de F. y Letras, 1933 (Sign. 674-8) (Legajo 1830)».

${ }^{9}$ Agradezco mucho a la prof. ${ }^{\text {a }}$ C. Castillo Castillo que obtuviera y me enviara las fotocopias correspondientes, además de señalarme el libro de Ramallo Ortiz, J. A., Catálogo de Profesores de la Universidad de Granada (1845-1935), con un estudio preliminar por Rafael Gibert, Catedrático de Historia del Derecho, Granada, 1976, donde hay una escueta referencia a S. Vila (en pág. 74).

10 «Evocación», 173.

${ }^{11}$ En su citado y completo estudio «Salvador Vila Hernández», espec. 48.
} 
El ambiente intelectual del que pudo participar Salvador Vila fue, en su marco general, de extraordinaria vitalidad cultural. Esas primeras décadas de nuestro siglo suelen calificarse, dentro de nuestra cultura, como «Edad de Plata», y tuvo características y alcances bien conocidos y reconocidos, como también lo son el grupo de sus no pocos protagonistas, desde los más famosos (Giner de los Ríos, Unamuno, Ortega, Américo Castro...), hasta la cantidad - comparativamente importante- de intelectuales destacados, especialistas en múltiples aspectos de las ciencias y las letras. El positivo ambiente y logros de esas primeras décadas del siglo $\mathrm{Xx}$, en España, que coinciden con la vida de Salvador Vila, han sido recientemente evocadas, una vez más, con voz muy sincera y muy directa, por David Castillejo ${ }^{12}$, situándonos en la forma con que aquellos intelectuales enfocaron las circunstancias —otra vez digo: intelectualmente extraordinarias y fecundas- que vivían:

«Durante un cuarto de siglo, entre 1910 y 1936, España disfrutó una verdadera libertad cultural, cuando un pequeño grupo de investigadores, pedagogos y escritores en torno a la Institución Libre de Enseñanza formaron la Junta para Ampliación de Estudios e Investigaciones Científicas, y ésta, a su vez, montó el Centro de Estudios Históricos, la Residencia de Estudiantes y varios laboratorios, fuera del círculo oficial de las Universidades.... La Junta envió al extranjero una selección cuidadosa de personas para recibir formación en centros alemanes, ingleses, franceses e italianos, mientras creaba sus propios centros de investigación en Madrid sobre la base de un modelo de colaboración intelectual pocas veces visto en los tiempos modernos. Estos intelectuales españoles, por vez primera, podrían organizar su propia vida, desarrollar sus proyectos y ayudarse mutuamente, libres de las cadenas de la burocracia y del poder político. Este movimiento produjo, por algún tiempo, un resurgir del pensamiento en España, que casi podría ser calificado de nueva edad de oro. Pero su labor fue anulada por la guerra civil y por la etapa subsiguiente».

El párrafo de D. Castillejo, que acabamos de citar, nos ha situado en el centro y comprensión de las circunstancias de aquellos años en que Salvador Vila se formó y en los que se situó su trabajo universitario. Desconozco todavía, pese a las pesquisas que hasta ahora he realizado, si Salvador Vila tuvo relación directa con la Junta para Ampliación de Estudios. En principio hay que pensar

12 En la «Introducción general» al epistolario de su padre, cuyo tomo I se titula Un puente hacia Europa. 1896-1909. Los intelectuales reformadores de España. Epistolario de José Castillejo, Madrid, 1997; la cita pertenece a la 11. 
que sí tuvo alguna relación, por la importancia de la Junta, y por la posición intelectual en que se situó desde muy joven S. Vila ${ }^{13}$, que también marchó para ampliar estudios a centros de investigación europeos, como esta perspicaz Institución procuraba, y fue, concretamente, a la Universidad de Berlín, en el curso 1928-1929. Hasta que el dato pueda comprobarse, de forma personal y directa, cabe deducir que Salvador Vila estuvo, de alguna manera, vinculado a la calidad de estos afanes intelectuales, promovidos por la Junta, como lo estuvieron los maestros arabistas de entonces, y sobre todo Julián Ribera (18581934) y Miguel Asín Palacios (1871-1944), que trabajaron, durante algún tiempo, en el fecundo Centro de Estudios Históricos, fundado en 1910. Sin embargo, Vila no fue pensionado a Berlín por la Junta, sino «por la Universidad de Salamanca» ${ }^{14}$.

$\mathrm{Y}$ esa cita anterior de D. Castillejo nos ha situado, también, en el centro de las dimensiones políticas concurrentes. La cita, repitamos su última parte, terminaba diciendo: «Este movimiento produjo, por algún tiempo, un resurgir del pensamiento en España, que casi podría ser calificado de nueva edad de oro. Pero su labor fue anulada por la guerra civil y por la etapa subsiguiente».

Salvador Vila fue una de las víctimas de la guerra civil, en 1936, como también lo fue otro arabista, Melchor Martínez Antuña. A cada uno le correspondió asumir —o ser asumido ${ }^{15}$ - por uno de los dos bandos en litigio, y caer aniquilado por el bando contrario. La reflexión de Ibn Hazm no puede ser más exacta: en la Córdoba andalusí, sacudida por la fitna de principios del siglo XI, Ibn Ḥazm advirtió, con razón, que «la flor de la guerra civil es infecunda». Esta advertencia es universal y eterna.

La prestigiosa Junta para Ampliación de Estudios, creada en 1907, procuraba que sus pensionados en el extranjero, en materias de derecho y filosofía, ampliaran conocimientos en Alemania, lo cual ya estaba en las directrices iniciales del gran educador Giner de los Ríos, él mismo profesor de Derecho, que

${ }^{13}$ B. López García analiza esta posición con mucha precisión, en su citado artículo sobre Salvador Vila.

${ }^{14}$ Así lo precisa su «Hoja de Servicios»; agradezco además a David Castillejo que consultara el centenar de fichas sobre pensionados de la Junta, guardadas en la Residencia de Estudiantes de Madrid, y comprobara que el nombre de S. Vila no aparece entre los pensionados de la Junta.

${ }^{15}$ B. López García, op. cit., 48: «En lo que respecta a la ideología de Salvador Vila, bien poco he podido concretar. No hay duda de su ideario republicano como prueba la aceptación del cargo de rector en circunstancias tan conflictivas... Sus amigos militaban a la izquierda. Su trayectoria había sido consecuente con esta línea. Sin embargo, no he encontrado ni en las encuestas ni en la prensa granadina de entonces ningún dato que revele una militancia determinada o unas simpatías concretas». 
así lo aconsejaba en carta a José Castillejo, uno de sus discípulos, doctorándose entonces en Derecho y pensionado también en la Universidad de Berlín; en su carta, Giner de los Ríos evocaba, exactamente, el interés de los estudios de Derecho en la Universidad de Berlín, en 1903. Claro está que estas alusiones preceden en veinticinco años al ambiente que allí, en Berlín, podría encontrar Salvador Vila, en el curso 1928-1929, pero reflejan las expectativas que un estudioso del Derecho había tenido, expectativas que se mantuvieron con más o menos intensidad, de modo que esos viajes de estudio a Berlín se siguieron cultivando. En 1903, Giner de los Ríos aconsejaba a José Castillejo que captara, precisamente en Berlín ${ }^{16}$, lo siguiente:

«De los civilistas, lo que más importancia, a mi entender, tiene para V. es: a) el modo de entender su Derecho privado...; b) el método de enseñanza tanto en clase como en los Seminarios; c) los consejos y direcciones privadas que en conversación puedan dar a V. acerca de libros, modo de trabajar, cursos que en Alemania puedan serle útiles, etc. etc. En Berlín mismo... tiene V. ahora cursos de H. ${ }^{a}$ del Derecho de Kohler y de Paulsen... También podría V. aprovechar, aconsejado por Kohler, un elemento que aquí no se conoce y que él, Post y otros - continuado por Stimmetz - han traído al derecho comparado, que es el estudio del derecho de los pueblos orientales... estudiado por juristas y civilistas, no por sociólogos.... Mi firme opinión de siempre es que el especialista debe ser hombre: a) de cultura filosófica; b) de cultura general; c) todo ello, viniendo a reforzar - además de servirle para ensanchar y formar (um zu bilden) su espíritu y darle un sentido abierto, universal, humanoa reforzar, digo su especialidad, sin la cual caería fácilmente en disipación y diletantismo».

En esta recomendación se contienen referencias muy interesantes, porque son relacionables con aspectos estudiosos que, a falta de otras pistas más directas, podemos situar entre las perspectivas intelectuales de comienzos del siglo $\mathrm{xx}, \mathrm{y}$ directamente actuantes aún en los años veinte y treinta de este siglo, $\mathrm{y}$ por tanto sobre el ambiente general en que se formó Salvador Vila, y también muy a propósito de nuestros temas especializados. En ese párrafo citado, se encomia la atención hacia la Historia del Derecho, el cuidado por el Derecho comparado y la importancia acordada dentro de él al «estudio del derecho de los pueblos orientales», además de indicar la forma de encajarlo intelectualmente, explícita en la parte final de la cita.

${ }^{16}$ Un puente hacia Europa. 1896-1909; la cita pertenece a las pp. 187-188. 
Por otra parte, el ambiente estudioso del arabismo alemán, que en el Curso 1928-1929 encontraría en Berlín, o en Alemania, Salvador Vila, ha sido muy bien analizado por Baber Johansen, «Politics and Scholarship: the development of Islamic Studies in the Federal Republic of Germany» ${ }^{17}$, que pone de manifiesto algunos nombres de especialistas ${ }^{18} \mathrm{y}$, sobre todo, la evolución que los estudios experimentaban por entonces en Alemania, donde el siglo xx había traído el reconocimiento generalizado de que los estudios árabes debían estar desarrollados por arabistas, y cómo esta especialidad ampliaba sus campos de intereses, y se subdividía en toda su gama de especialidades, las cuales requerían, a su vez, y en muchas ocasiones, un doble conocimiento.

Licenciado en Derecho y doctor en Filosofía y Letras, Salvador Vila reunía, pues, este doble conocimiento, tan conveniente - de jurisperito y arabis$\mathrm{ta}^{19}$-para dedicarse a trabajar sobre el Derecho islámico. No sabemos con precisión cómo y cuándo se decidió por esta especialización, ya marcadísima desde su Tesis Doctoral, presentada en abril de 1927, sobre los wațā'iq de Ibn Mugit. Con esta decisión, Salvador Vila se situaba en el marco general del arabismo español, que había dado sus «first steps» en el estudio científico del Derecho islámico desde mediados del siglo $\mathrm{XIX}^{20}$, y en el marco más concreto, dentro de ese marco general, del trío de especialistas constituido por José López Ortiz (1898-1992), Melchor Martínez Antuña (m. en 1936), y por el mismo Salvador Vila; la situación personal y estudiosa de los tres, en su conexión, ha sido muy bien analizada por Maribel Fierro, en su citado artículo «Spanish scholarship on Islamic Law» ${ }^{21}$, resaltando su condición común de constituir un trío de especialistas muy importante en los estudios del Derecho Islámico, truncado desde 1936, en los casos de Martínez Antuña y Vila por su muerte, entonces, y en el López Ortiz por una nueva orientación profesional, que le llevó a abandonar los estudios árabes desde la segunda mitad de los años cuarenta.

${ }^{17}$ En Tareq Y. Ismael (Ed.), Middle East Studies. International Perspectives on the State of the Art, New York, Westport, Connecticut, London, 1990, 71-130.

${ }^{18}$ C. H. Becker (1876-1933); Hans Heinrich Schaeder (1896-1957). Sobre cuestiones de Derecho, publicaban en alemán, hacia 1925-1930: G. Jacob, E. Pröbster y O. Spies, además del citado Becker.

${ }_{19}$ Fierro, M., «Spanish scholarship on Islamic Law», 56, y nota 60: «Writing about S. Vila in 1976, the legal historian J. M. Pérez Prendes stated that we still lack a history of the legal institutions of al-Andalus, carried out by an Arabist who knows law or by a jurist who knows Arabic. Such a book might have been written by S. Vila».

${ }^{20}$ Fierro, M., «Spanish scholarship on Islamic Law», 46-49: 'The First Steps'.

${ }^{21}$ Idem, 49-56: «The Ill-fated Coming of Age: J. López Ortiz, M. M. Antuña, S. Vila». 
Me gustaría poder plantear con cierta amplitud significativa las relaciones entre los tres ${ }^{22}$. Casi no quedan datos. Está claro que López Ortiz y Martínez Antuña precedían cronológicamente a Vila, pero que entre todos ellos se anudaron relaciones positivas. Son especialmente significativas las vinculaciones entre López Ortiz y Vila ${ }^{23}$, porque en Martínez Antuña la dedicación al Derecho islámico fue sólo parcial, y por tanto los otros dos debieron compartir más relación y coordinarse más; el espíritu de colaboración entre López Ortiz y Vila, y la situación de reconocimiento del segundo al saber del primero, se manifiesta, por ejemplo, en carta manuscrita de Vila a López Ortiz ${ }^{24}$, fechada en Granada, el 4 de junio de 1935, donde Vila le cuenta cómo continúa trabajando sobre «Abenmoguit», y le consulta: « $i$ Tiene Vd. noticias de ese libro de Schacht sobre los formularios? ¿Tiene Vd. una bibliografía un tanto completa del tema? Porque traducido completamente el I. Mugit —espero terminar la $1 .^{\text {a }}$ traducción este verano- y a mi disposición los demás formularios — los de la Junta-, quisiera hacer en la Introducción una nota relativamente completa. Y Vd. que es historiador del Derecho por los cuatro costados -0 al menos por dos, por oriente y por occidente- sabrá cuáles son las obras fundamentales también sobre formularios no islámicos....».

Es lógico que Vila reconociera la precedencia de López Ortiz, respecto a su principal especialización, que eran los formularios notariales o kutub al-wațâ'iq, sobre los que López Ortiz había escrito páginas importantes, publicadas desde $1926^{25}$, y sobre los que Vila trabajó a su vez, en su citada Tesis Doctoral, presentada en abril de 1927, y publicada, con fecha de 1931, en un estudio de 201 páginas, sobre «Abenmoguit. Formulario Notarial. Capítulo del matrimonio» ${ }^{26}$, donde edita y traduce esa parte de al-Muqni' ${ }^{\prime}$ ' ${ }^{\prime} \mathrm{llm}$ al-šurūt, del toledano Ibn Mugīt (siglo IV/XI), con una «introducción» (pp. 5-48) sobre esa obra y cuanto representa, además de un análisis pormenorizado del contenido. Vila continuó luego

\footnotetext{
22 El planteamiento sería ampliable a las relaciones que se establecieron entre el número, importante, de arabistas que coincidieron en aquellos años treinta del arabismo español. Además de lo que, sobre tales relaciones, recuerda Bernabé López García, en su citado artículo, obsérvese que el ejemplar de la obra de Vila, Abenmoguit. Formulario Notarial, conservado en el «Legado Asín», está dedicado «A mi querido maestro D. Maximiliano Alarcón con el afecto de siempre. Salvador Vila».

23 Véase la reseña laudatoria de López Ortiz al Abenmoguit: Formulario notarial de S. Vila, en Al-Andalus, I (1933), 227; y las cuatro, en general admirativas, reseñas de Vila sobre trabajos de López Ortiz (las citamos en el apartado final de la «bibliografía» de S. Vila).

${ }^{24}$ La carta se conserva manuscrita en el interior del volumen de Abenmoguit. Formulario Notarial (Biblioteca del Instituto de Filología del Consejo Superior de Investigaciones Científicas, Madrid), según me comunica la Dra. Amalia Zomeño, quien amablemente me ha enviado fotocopia de la misma.

25 Fierro, M., «Spanish scholarship on Islamic Law», 67.

26 Sobre este autor y su obra, véase ahora, Kitāb al-Muqni' fì 'ilm al-šurūt (Formulario notarial), de Ibn Mugit, ed. F. J. Aguirre, Madrid, 1994.
} 
sus pesquisas sobre el tema —-según vimos en el párrafo anterior-, ampliando la cuestión de formularios y actas notariales hasta la época morisca, al publicar, en 1933, «Un contrato de matrimonio entre musulmanes del siglo XVI» ${ }^{27}$. Apuntemos además que Vila inició sus publicaciones sobre instituciones políticas con su minucioso estudio sobre «El nombramiento de los wālíes de alAndalus». Expresó muchas de sus consideraciones respecto al Derecho islámico en algunas reseñas aparecidas en la revista Al-Andalus, creada en 1933, y en cuyo «Consejo de Redacción» participó Salvador Vila desde el primer número (Madrid-Granada, 1933) junto con M. Martínez Antuña, R. García de Linares, A. González Palencia, J. López Ortiz, N. Morata y R. Ruiz Orsatti ${ }^{28}$, además de los directores M. Asín Palacios y E. García Gómez, integrado, pues, Salvador Vila, en el núcleo central del arabismo español de aquellos años. Su nombre figuró entre los «Redactores» de Al-Andalus hasta el IV $(1939)^{29}$.

Esta «ill-fated» o malograda generación de estudiosos españoles del Derecho islámico, tan activa en los años treinta, con López Ortiz, Martínez Antuña y Vila, representa el cultivo de estos temas por unos especialistas que conocían la lengua y cultura árabes y tenían más o menos nociones, además, de Derecho, en general, con lo cual apuntaron el mejor modelo a seguir. Iniciaron, con el eje consagrado de López Ortiz, con el complemento de Martínez Antuña, y con la prometedora actividad de Vila, un cultivo sistemático y coherente del Derecho islámico en España, y su esfuerzo, interesantísimo, quedó como ejemplo y prueba de posibilidades que, sobre todo, empezaron a ser retomadas cuarenta años después en la serie de Tesis Doctorales propiciadas por Jacinto Bosch Vilá en la Universidad de Granada. Sus obras siguen siendo básicas, y por su valía y representación las tenemos en cuenta.

${ }^{27}$ Que ha presentado muy bien B. López García, artículo citado, pág. 47: «Se basa en un documento valenciano de 1568 y presenta para el autor el interés de comprobar «la persistencia de contenido y fórmulas», lo que a su juicio no quiere decir «invariabilidad muerta» con los modelos de la obra de Ibn Mugit, de cinco siglos antes, lo que permitiría establecer una línea de investigación en la comparación de formularios antiguos para comprobar las innovaciones y permanencias del derecho musulmán español a través de la larga presencia del Islam en España». Véase ahora, sobre esas actas: Ana Labarta, "Contratos matrimoniales entre moriscos valencianos», Al-Qantara, 4 (1983), 57-87.

${ }^{28}$ El Consejo de Redacción cambió desde el II (1934), fascículo 2 (incluyéndose entonces a L. Torres Balbás), más otros cambios en números siguientes.

${ }^{29}$ Que tuvo como redactores a: M. Alonso, R. García de Linares, A. González Palencia, J. López Ortiz, N. Morata, J. Oliver Asín, R. Ruiz Orsatti y L. Torres Balbás. 


\section{Bibliografía de Salvador Vila HernándeZ}

«Abenmoguit. Formulario Notarial. Capítulo del matrimonio», Anuario de Historia del Derecho Español, 1931, 201 páginas.

«Un contrato de matrimonio entre musulmanes del siglo XVI», Anuario de Historia del Derecho Español, X (1933), 186-196.

«El nombramiento de los wālíes de al-Andalus», Al-Andalus, IV (1936-1939), 215-222.

\section{TRADUCCIÓN}

Adam Mez, El renacimiento del Islam, con advertencia del traductor fechada en Granada, en diciembre de 1934, y publicada en Madrid, 1936.

\section{RESEÑAS}

La recepción de la Escuela malequí en España, por J. López Ortiz, en AlAndalus, I (1933), 227.

Mekka (trans. by J. H. Monahan), por C. Snouck Hurgronje, en Al-Andalus, I (1933), 475.

Derecho musulmán, por J. López Ortiz, en Al-Andalus, I (1933), 478.

La jurisprudencia y el estilo de los Tribunales musulmanes en España, por J. López Ortiz, en Al-Andalus, I (1933), 478.

The islamic background of Ibn Khaldun's political theory, por H. A. R. Gibb, en Al-Andalus, II (1934), 250.

El Tribunal de fe de los Omeyas cordobeses, por J. López Ortiz, en Al-Andalus, II (1934), 250.

\section{RESUMEN}

Se exponen las aportaciones científicas del arabista Salvador Vila Hernández (19041936), su dedicación docente e investigadora en las Universidades y Escuelas de Estudios Árabes de Madrid y Granada. Se sitúa su figura en el notable ambiente intelectual de aquellos años, en que se abrió de forma muy definida una especialización sobre Historia del Derecho y de las Instituciones islámicas, y especialmente en referencia a al-Andalus. 
ABSTRACT

This paper analyzes the scientific achievements of the noted arabist Salvador Vila Hernández (1904-1936), chiefly his dedication to research and teaching in the universities and Schools of Arabic Studies of Madrid and Granada. His work is placed in the intellectual context of those years, during which he initiated energetically the specialized study of the history of law and of Islamic institutions, especially with reference to al-Andalus. 